\title{
Insect reactions to light and its applications to pest management
}

\author{
Masami Shimoda $\cdot$ Ken-ichiro Honda
}

Received: 9 September 2013/Accepted: 24 September 2013/Published online: 11 October 2013

(C) The Author(s) 2013. This article is published with open access at Springerlink.com

\begin{abstract}
Insects are able to see ultraviolet (UV) radiation. Nocturnal insects are often attracted to light sources that emit large amounts of UV radiation, and devices that exploit this behavior, such as light traps for forecasting pest outbreaks, and electric insect killers, have been developed. Some diurnal species are attracted to yellow; yellow pan traps are used for conducting surveys for pest outbreaks and yellow sticky plates are used for pest control. Lamps that give off yellow illumination have been used effectively to control the activity of nocturnal moths and thus reduce damage to fruit, vegetables, and flowers. Covering cultivation facilities with film that filters out near-UV radiation reduces the invasion of pests such as whiteflies and thrips into the facilities, thus reducing damage. Reflective material placed on cultivated land can control the approach of flying insects such as aphids. Future development and use of new light sources such as light-emitting diodes is anticipated for promoting integrated pest management.
\end{abstract}

Keywords Integrated pest management - Artificial lighting $\cdot$ Photoreception $\cdot$ Phototaxis $\cdot$ Light-emitting diode

M. Shimoda $(\bowtie)$

National Institute of Agrobiological Sciences, 1-2 Ohwashi, Tsukuba, Ibaraki 305-8634, Japan

e-mail: shimoda1@affrc.go.jp

K. Honda $(\bowtie)$

Agricultural Research Center, National Agriculture and Food Research Organization, 3-1-1 Kannondai, Tsukuba, Ibaraki 3058666, Japan

e-mail: khonda@affrc.go.jp

\section{Introduction}

Most insects have two types of photoreceptive organs, compound eyes and ocelli. Compound eyes are made up of a large number of light-sensitive units termed ommatidia. An ommatidium contains an elongated bundle of photoreceptor cells, each having specific spectral sensitivities. The ommatidia are packed in a hexagonal array so as to cover a large visual field with certain spatial resolution and to perceive the motion of objects (Land and Nilsson 2002). The spectral sensitivities of photoreceptors determine the visible light wavelength for insects, which often expands into the ultraviolet (UV) region, which is invisible to humans. A compound eye typically contains three types of photoreceptor cells with spectral sensitivity peaking in the $\mathrm{UV}$, blue, and green wavelength regions, respectively, as exemplified in honeybees (Fig. 1) (Menzel and Blakers 1976). But even in the order hymenoptera, some sawflies have been shown to have red receptors as well (Peitsch et al. 1992). At any rate, it is likely that many insects can perceive UV light as a unique color (Koshitaka et al. 2008; von Helversen 1972).

It is well known that insects fly toward streetlamps or other outdoor illumination at night. This innate phototactic behavior has provided the basis of the design of electric insect killers. Equipped with UV-emitting fluorescent tubes, the insect killers effectively attract insects such as moths and beetles and prevent these insects from entering into greenhouses and stores that are open at night. In recent years, considerable interest has been generated in pest control technology that utilizes the responses of insects to light as a "clean" form of pest control that does not use synthetic pesticides (Antignus 2000; Ben-Yakir 2013; Emura and Tazawa 2004; Honda 2011; Johansen et al. 2011; Tazawa 2009). Here, we 


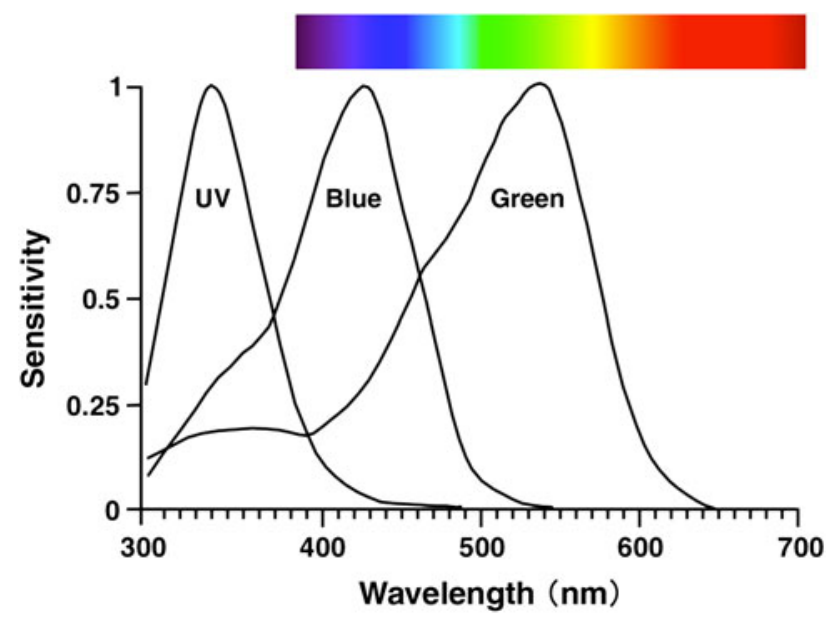

Fig. 1 Spectral sensitivity curves of three types of photoreceptor cells ( $U V$, blue, green) of the honeybee Apis mellifera (modified from Peitsch et al. 1992). The $U V$-, blue-, and green-sensitive photoreceptors of the genus Apis are typical for many insects. A spectrum shown above is a human visible light region

review recent advances of pest control technologies that employ this method.

\section{Influences of light on insect behavior and development}

Light affects insect behavior and development in a variety of ways that can be divided into several categories (Fig. 2). One of the most typical responses to light is phototaxis (Jander 1963). Insects exhibit the following phototactic behaviors: (A) attraction (i.e., positive phototaxis, moving toward a light source) (Fig. 2a); this response can be used to trap pests, but the effective wavelengths and intensities vary among species (Coombe 1981; Hardie 1989; Kinoshita and Arikawa 2000; Menzel and Greggers 1985; Yang et al. 2003) and (B) repulsion (i.e., negative phototaxis, moving away from light) (Fig. 2b); this can be used to prevent pests from entering a cultivation area by presenting light at wavelengths and intensities that repel them (Jander 1963; Kim et al. 2013; Reisenman et al. 1998).

There are a wide range of responses to light beyond phototaxis. (C) Light adaptation is when nocturnal insect species become light-adapted within several minutes of exposure to light (Day 1941; Post and Goldsmith 1965; Walcott 1969) and exhibit typical daytime behaviors such as cessation of movement and settling down (Fig. 2c). Behaviors such as flight and mating are inhibited in nocturnal insects that are exposed to bright light at night. (D) Circadian rhythms are daily behavioral rhythms including flight, locomotion, feeding, courtship, mating, etc. (Fig. 2d) (Bateman 1972; Shimoda and Kiguchi 1995). Artificial lighting for a certain duration during the night can shift the timing of the diurnal/nocturnal behaviors of insects (Okada et al. 1991). This response is called a "phase shift" in chronobiology (Pittendrigh 1993; Truman 1976). (E) Photoperiodicity is the physiological response of insects to the light schedule (i.e., day length). The onset of diapause can be prevented by exposing insects to light repeatedly for several days (Masaki 1984; Saunders 2012). Insects that do not enter dormancy are unable to overwinter (Fig. 2e). (F) Light toxicity occurs when the retinas of compound eyes of an insect exposed to UV and blue light radiation are damaged and structurally degenerated (Meyer-Rochow et al. 2002; Stark et al. 1985). Furthermore, some insects are unable to undergo normal development or survival (Fig. 2f) (Ghanem and Shamma 2007; Siderhurst et al. 2006; Zhang et al. 2011). Such photoirradiation can also be used for post-harvest treatment of crops. (G) Insects will not actively fly toward something they cannot see (i.e., invisible). That is, by covering a greenhouse with UV-blocking film, plants inside can be made invisible to insects. As a result, pests will not enter the greenhouse (Fig. 2g) (Antignus et al. 1998; Legarrea et al. 2010). (H) Finally, some free-flying insects show a dorsal light reaction, where they stabilize their horizontal orientation (attitude) by perceiving light that shines on their dorsal side as sunlight does during flight (Jander 1963). The ability to control roll by means of the dorsal light reaction is known for many flying insects such as dragonflies and desert locusts (Goodman 1965; Neville 1960). By covering the ground with a highly reflective mulching sheet, the normal orientation of flight is disturbed by light reflected from below (Fig. 2h). These last two effects of light are useful to prevent insects from entering a cultivation area.

These responses to light are substantially influenced by a variety of factors, including light intensity and wavelength, combinations of wavelengths, time of exposure, direction of light source, and the contrast of light source intensity and color to that of ambient light. In addition, the impact of light on insect behavior varies both qualitatively and quantitatively depending on the light source (light bulb or light-emitting diode [LED]) and material (light-reflecting plate) (Antignus 2000; Coombe 1981, 1982; Honda 2011; Johansen et al. 2011; Matteson et al. 1992; Nissinen et al. 2008; Prokopy and Owens 1983; Smith 1976). In the remainder of this review, we discuss examples of technologies that are currently being used to control a variety of pests.

\section{Attraction of insects to light sources at night}

The Japanese saying, "flying like an insect in summer into the fire," speaks of unwittingly rushing to one's doom by being drawn into a deadly situation. Many nocturnal insect 
Fig. 2 Typical responses of insects to light. a Positive phototaxis, b negative phototaxis, c light adaptation, d disturbance of circadian rhythm and e photoperiodicity. f Toxicity of UV on growth and development. g Visibility control with UV-blocking film. h Dorsal light reaction

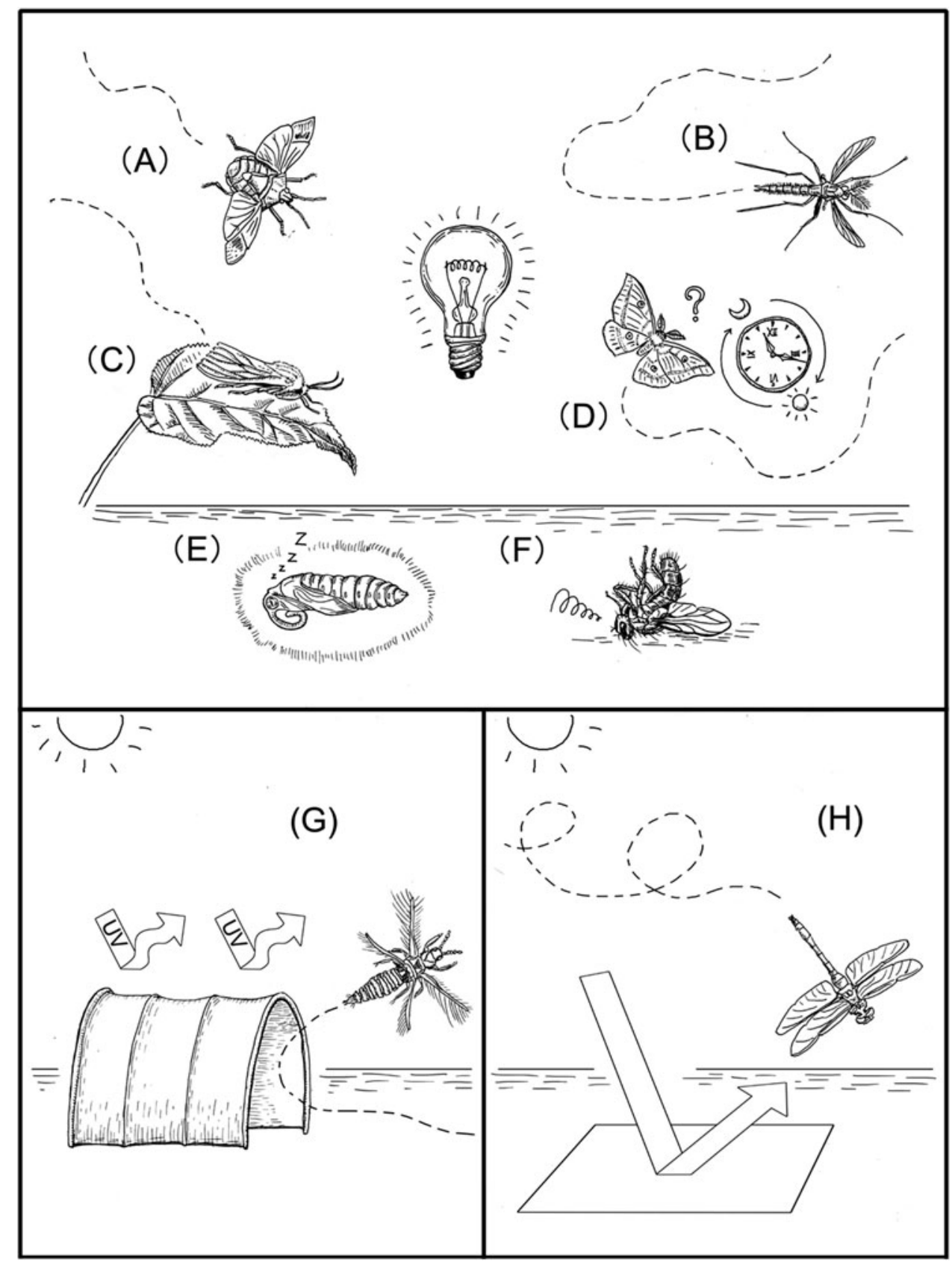

species such as moths, beetles and stinkbugs are attracted to artificial light sources. Of the light sources that attract nocturnal insects, those that emit relatively large amounts of UV radiation (blue fluorescent lights, black lights, and mercury lamps) exert the strongest attraction (Aoki and Kuramitsu 2007; Cowan and Gries 2009; Matsumoto 1998). Insect light traps using blue fluorescent light were used widely to control rice stem borer, Chilo suppressalis Walker, and Tryporyza incertulas Walker moths in paddy fields across Japan during World War II and the postwar period (Ishikura 1950). The Ministry of Agriculture, Forestry, and Fisheries (MAFF) of Japan has established survey methods for forecasting pest outbreaks employing incandescent lights, mercury lamps, and black lights at pest control stations around the country (a light trap with an incandescent light is shown in Fig. 3). Identity and number data for each insect species are used to forecast pest outbreaks (Katayama et al. 1993; Matsumura 2001). Furthermore, various electric insect killers that use light sources exerting a strong attraction on insects have been developed. These devices are put to practical use for pest control at greenhouses and at stores that are open at night (a large electric insect killer used in a hotel garden in China is shown in Fig. 4). 


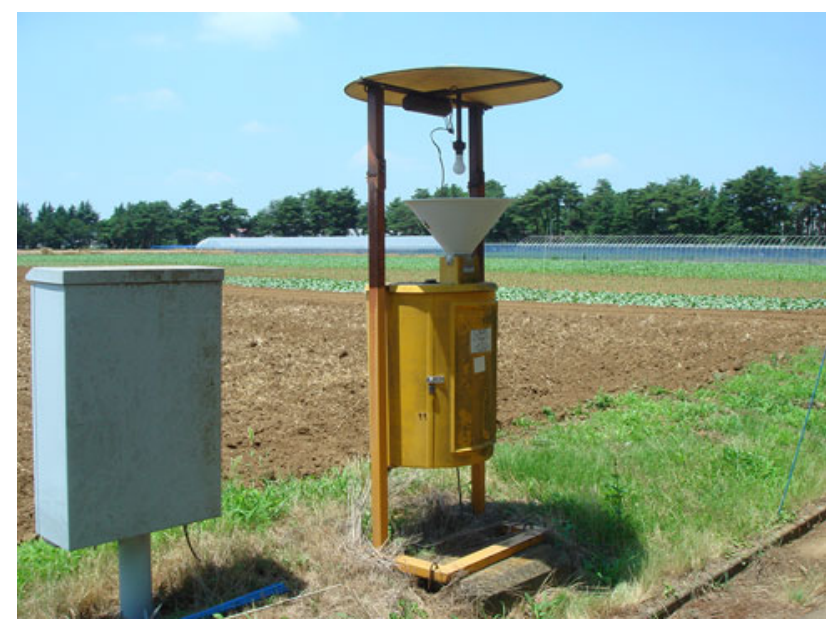

Fig. 3 A light trap that uses an incandescent light. Data on numbers of single insect species are used to forecast pest outbreaks

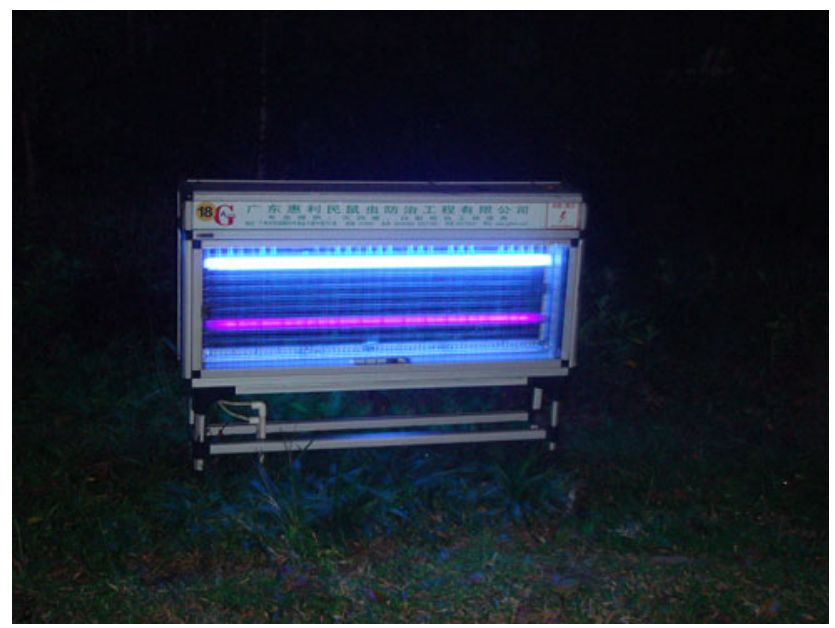

Fig. 4 A large electric insect killer used in a hotel garden in China

\section{Attraction of insects to color plates}

Some diurnal insects can be attracted to light sources at night. However, due to the intensity of sunlight, artificial light sources are less effective (or not effective at all) for pest control during the day. To capture diurnal pests, the use of colored devices, such as yellow pan traps or yellow sticky traps, is well known: a yellow pan trap for forecasting aphid outbreaks is shown in Fig. 5. Insects that are attracted to these yellowish devices include important crop pests such as planthoppers, leafhoppers, aphids, whiteflies, thrips, and leafminer flies (Esker et al. 2004; Mainali and Lim 2010; Vaishampayan et al. 1975). Yellow sticky plates or rolls have become important tools for the physical control of these pests (Tokumaru et al. 2009): those in use at a tomato cultivation facility are shown in Fig. 6.

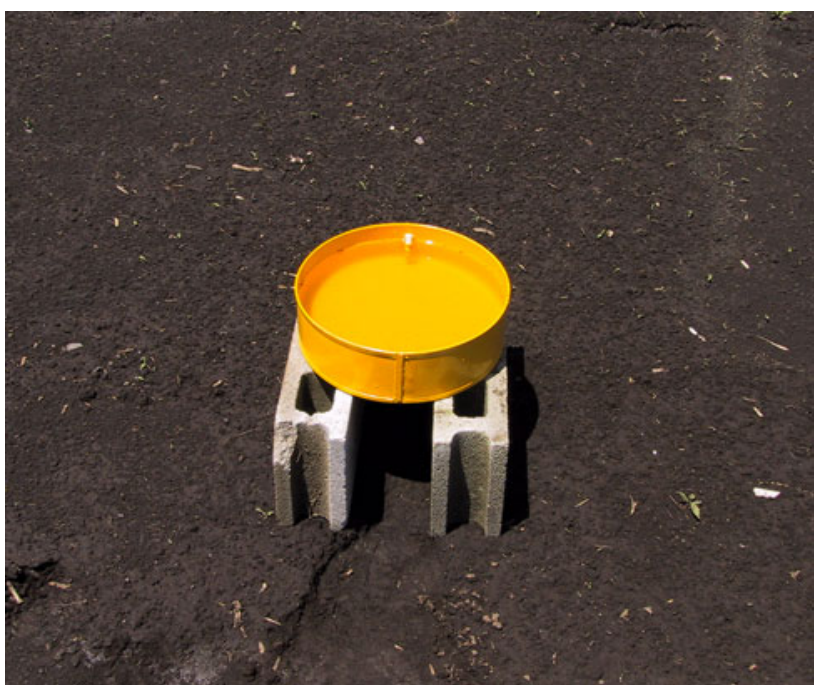

Fig. 5 A yellow pan trap for forecasting aphid outbreaks
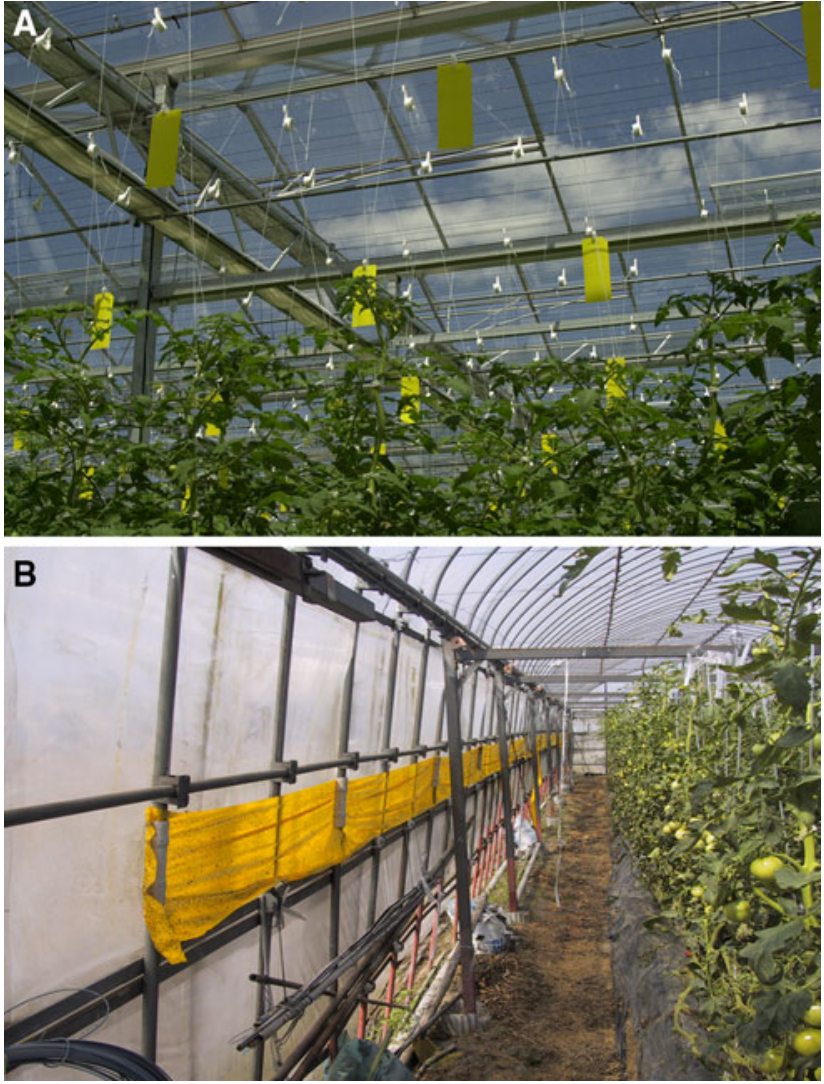

Fig. 6 Yellow sticky plates (a) and rolls (b) in use at a tomato cultivation facility for the physical control of pests, mainly whiteflies and thrips

\section{Suppression of nocturnal insect activities by yellow light}

Fruit-piercing moths such as Eudocima tyrannus Guenée and Oraesia emarginata Fabricius damage fruit in orchards. Damage can be prevented by running yellow 
Fig. 7 The compound eye of the nocturnal moth, Helicoverpa armigera, in the light-adapted (left) and dark-adapted (right) states (photo courtesy of Junya Yase)

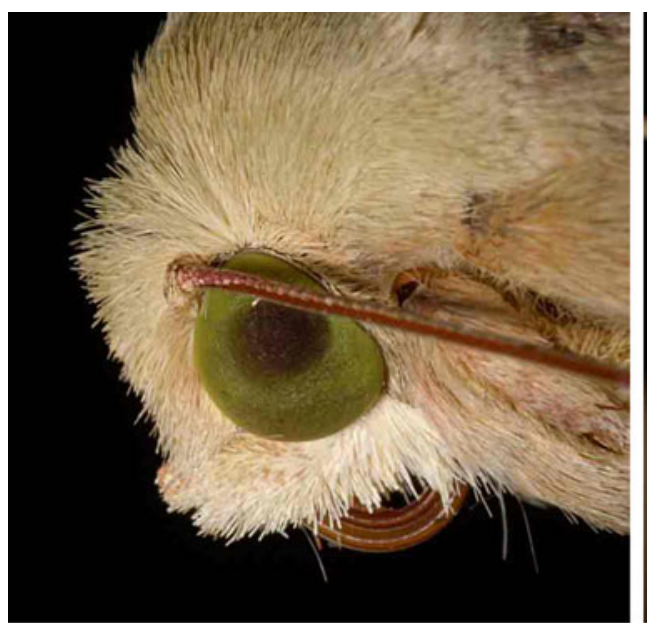

Light-adapted

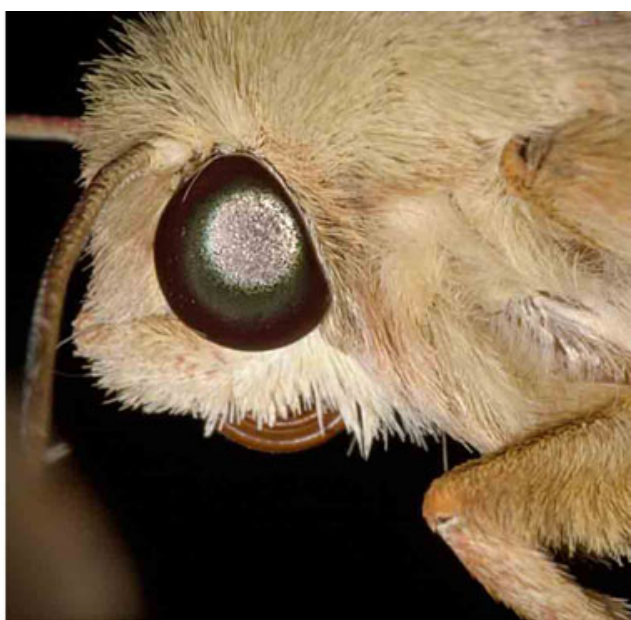

Dark-adapted
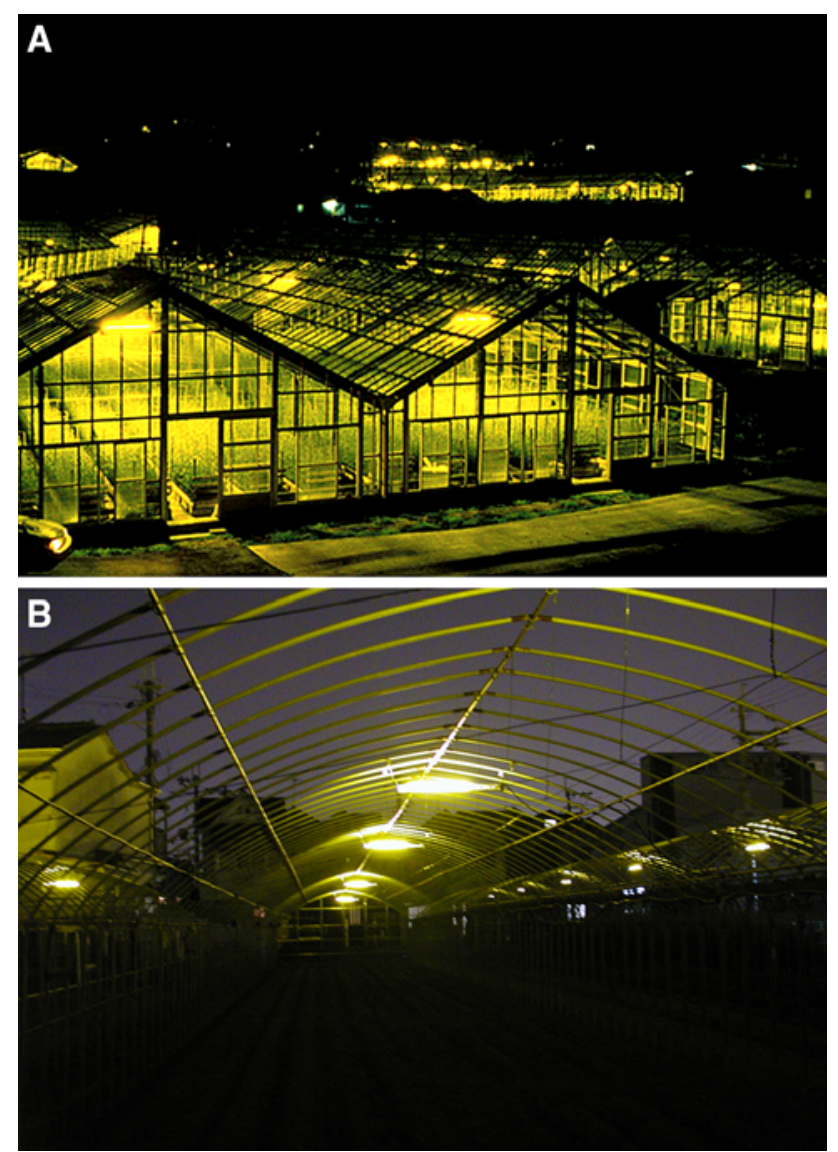

Fig. 8 Flower cultivation facilities with yellow fluorescent lamps (a: carnation facilities, photo courtesy of Junya Yase; b: chrysanthemum facilities, photo courtesy of Manabu Shibao)

fluorescent lamps in the orchard at night (Nomura 1967; Nomura et al. 1965). This strategy makes use of the fact that when moths encounter light above a certain brightness at night, under which their compound eyes are lightadapted as in the daytime (Meyer-Rochow 1974; Walcott
1969), the light adaptation suppresses nocturnal behaviors such as flying, sucking the juice of fruit, and mating. This technique of suppressing behavior using yellow fluorescent light is also used to prevent damage to chrysanthemums and carnations by the cotton bollworm Helicoverpa armigera Hübner (Yase et al. 1997), damage to green perilla by the common cutworm Spodoptera litura (Fabricius), and damage to cabbage by the webworm, Hellula undalis Fabricius (Yase et al. 2004). The light-adapted and darkadapted states of the compound eye of adult Helicoverpa armigera are shown in Fig. 7. Recently, green fluorescent lamps have also been developed for the control of nocturnal moths. These lamps suppress the behavioral activity of a number of moth species in the same way as yellow fluorescent lamps but have little effect on the growth of plants compared to the yellow lamps (Yamada et al. 2006; Kono and Yase 1996; Yase et al. 1997) (Fig. 8). Furthermore, because LED lighting is becoming considerably cheaper, yellow-emitting LEDs have been recently applied to control the behaviors of nocturnal moths (Hirama et al. 2007; Yabu 1999; Yoon et al. 2012). LEDs can produce highly monochromatic lights (i.e., with a narrow range of wavelength) across the spectrum from UV to red. This optical characteristic of LEDs is an advantage for controlling pest behavior and their practical application is expected in the near future.

\section{Control of pest infestation using UV-absorbing films}

The use of UV-absorbing plastic films that block near-UV light radiation (300-400 $\mathrm{nm}$ ) in greenhouse cultivation has been shown to be effective for preventing different types of pests from entering greenhouses (Nakagaki et al. 1982, 1984; Raviv and Antignus 2004). Insect eyes are highly sensitive to near-UV light radiation and vision in the UV 


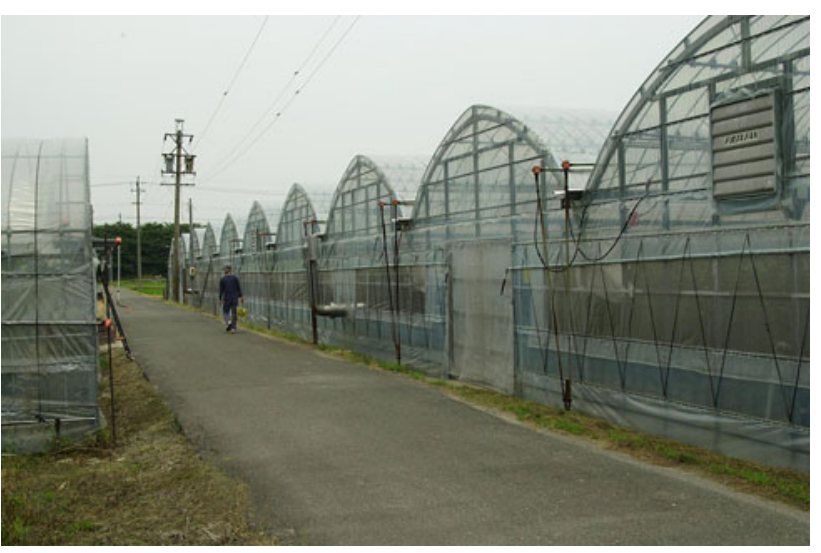

Fig. 9 A greenhouse covered with UV-absorbing plastic film

range is important for orientation in many species (Prokopy and Owens 1983). A greenhouse covered with UVabsorbing film is hypothesized to appear dark for these insects. For insects given access to a space with UV radiation and a space from which near-UV radiation was eliminated, many species avoid the latter. Studies have shown reduced incidence of insects such as aphids, whiteflies, and thrips in facilities covered with UVabsorbing film (Costa et al. 2002; Nguyen et al. 2009; Nonaka and Nagai 1985; Ohta and Kitamura 2006). In addition to vinyl chloride films, products made of highly durable polyolefin films have recently been developed to block near-UV radiation, to prevent infestation inside greenhouses. Honeybees, which play an important role in pollination, also become inactive in facilities covered with near-UV ray absorbing film, so caution is needed when pollinating insects are used in greenhouses: a plastic greenhouse covered with UV-absorbing film is shown in Fig. 9.

\section{Inhibition of flight by reflective mulching films}

The use of mulching films that reflect light in open crop fields is known to suppress the arrival of alate aphids (e.g., Fig. 10 shows a soybean field covered with a silver mulch sheet; Kimura 1982). Spreading reflective sheets over the ground surface has also been reported to control the invasion or outbreak of thrips and whiteflies (Nagatuka 2000; Simmons et al. 2010; Tsuchiya et al. 1995). The mechanism by which reflecting light controls the invasion of these pests is not yet fully understood. Some free-flying insects exhibit the dorsal light reaction, as described above (Goodman 1965; Jander 1963; Neville 1960). They stabilize their horizontal orientation by the light shining on their dorsal side, as happens with light from the sun when flying, but they become unable to continue normal flight when the light comes from the ground. By covering the ground with

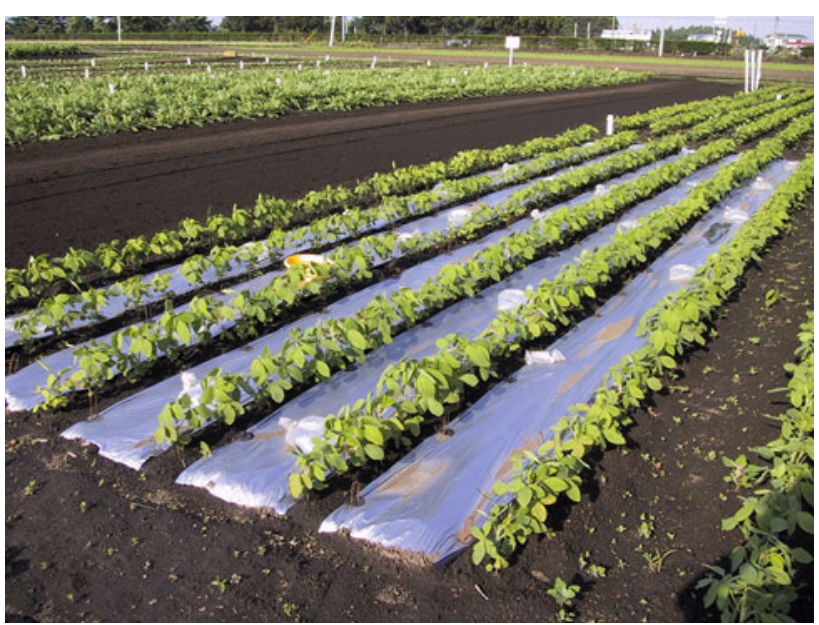

Fig. 10 A soybean field covered with silver mulching sheets

highly reflective mulching sheet, the light reflection from below disturbs the normal orientation of flight.

\section{Current research on physical pest control using light}

The Ministry of Agriculture, Forestry and Fisheries of Japan has been implementing a research project called "Elucidation of biological mechanisms of photoresponse and development of advanced technologies utilizing light" since 2009 (Honda 2011). Understanding the light-response mechanisms of insects and developing advanced applied technologies are the main objectives of this project and research is underway toward the development of pest control technology using new light sources such as LEDs. The National Agriculture and Food Research Organization (NARO) of Japan is the core research institution for this project and more than 20 research groups including universities, independent administrative institutions, public research institutes, and companies participate. The main areas of research include basic research on reaction behavior, color perception, and polarized light perception with light of different wavelengths; the development of outbreak forecast technology using new light sources; and the development of pest control technology using new light sources. In the project, we have set three research areas.

For the first research area, electrophysiological techniques are being used to comprehensively measure the sensitivity of different pests over a wide range of light wavelengths. In addition, the responses of stinkbugs, thrips, whiteflies, planthoppers, leafhoppers, and other species to LEDs and other light sources are being studied to clarify the relationship between light wavelength and the behavioral ecology of pests. This area of research is aimed at determining the wavelengths that are effective for attracting or repelling pests as well as those that affect behavioral 
activity and orientation to the light (Hironaka and Hariyama 2009).

The second research area includes the development of LED light sources that can be used in place of incandescent lights to forecast agricultural pest outbreaks as well as the investigation of outdoor devices (light sources and traps) that can be used in places with no electricity. Beneficial insects such as parasitoid wasps that are natural enemies of pests will also be studied to determine the light wavelengths that attract them effectively. Studies are also investigating the development of fundamental technologies for devices to survey and collect natural enemies. Moreover, devices that effectively attract biting midges, which play an important role as vectors for viral diseases in livestock, will be developed to survey outbreaks.

For the third research area, behavioral effects such as attraction or repulsion associated with different wavelengths of light are being analyzed for whiteflies, thrips, and leafminer flies, which damage vegetables grown in greenhouses; lepidopteran pests of bare-earth vegetables and tea; Asian citrus psyllids for citrus fruit; fungus gnats for cultivated mushrooms; and green chafers for sugarcane. New pest control technologies for these pests include the use of LEDs. LED lighting devices that take up little space and have low energy consumption are likely to enable pest control in places where conventional light sources are impractical. At the same time, studies are being carried out to investigate the wavelengths that are effective against pests but have little effect on the cultivation of crops. This research area aims to develop a new pest control technology that is fully compatible with cultivation technology.

\section{Conclusion}

LED devices with various wavelengths can now be manufactured due to recent technological advances, and new agricultural technology using light is starting to attract attention. Advances are also expected in the use of light for pest control as a result of these technological developments in lighting. Based on the new research being conducted by NARO, we hope to ensure the further development of applied technology founded on a good balance of input from basic research in universities and independent administrative institutions and applied technology from public research institutes and private companies to establish the next generation of pest control technology.

Acknowledgments This work was supported by a grant titled "Elucidation of biological mechanisms of photoresponse and development of advanced technologies utilizing light" from the Ministry of Agriculture, Forestry and Fisheries (MAFF), Japan and JSPS KAKENHI Grant Number 25660268.
Open Access This article is distributed under the terms of the Creative Commons Attribution License which permits any use, distribution, and reproduction in any medium, provided the original author(s) and the source are credited.

\section{References}

Antignus Y (2000) Manipulation of wavelength-dependent behavior of insects: an IPM tool to impede insects and restrict epidemics of insect-borne viruses. Virus Res 71:213-220

Antignus Y, Lapidot M, Hadar D, Messika Y, Cohen S (1998) Ultraviolet-absorbing screens serve as optical barriers to protect crops from virus and insect pests. J Econ Entomol 91:1401-1405

Aoki S, Kuramitsu O (2007) Development of insect-attracting lighting fixture and evaluation of insect attractiveness by a new index. J Illum Engng Inst Jpn 91:195-198

Bateman MA (1972) The ecology of fruit flies. Ann Rev Entomol 17:493-518

Ben-Yakir D, Antignus Y, Offir Y, Shahak Y (2013) Optical manipulations: an advance approach for reducing sucking insect pests. Adv Technol Manag Insect Pests 1:249-267

Coombe PE (1981) Wavelength specific behaviour of the whitefly Trialeurodes vaporariorum (Homoptera: Aleyrodidae). J Comp Physiol 144:83-90

Coombe PE (1982) Visual behaviour of the greenhouse whitefly, Trialeurodes vaporariorum. Physiol Entomol 7:243-251

Costa HS, Robb KL, Wilen CA (2002) Field trials measuring the effects of ultraviolet-absorbing greenhouse plastic films on insect populations. J Econ Entomol 95:113-120

Cowan T, Gries G (2009) Ultraviolet and violet light: attractive orientation cues for the Indian meal moth, Plodia interpunctella. Entomol Exp Appl 131:148-158

Day MF (1941) Pigment migration in the eyes of the moth, Ephestia kuehniella Zeller. Biol Bull 80:275-291

Emura K, Tazawa S (2004) The development of the eco-engineering insect control technology-physical control of insect behavior using artificial lights. Eco-engineering 16:237-240 (in Japanese with English abstract)

Esker PD, Obrycki J, Nutter FW (2004) Trap height and orientation of yellow sticky traps affect capture of Chaetocnema pulicaria (Coleoptera: Chrysomelidae). J Econ Entomol 97:145-149

Ghanem I, Shamma M (2007) Effect of non-ionizing radiation (UVC) on the development of Trogoderma granarium Everts. J Stored Prod Res 43:362-366

Goodman LJ (1965) The role of certain optomotor reactions in regulating stability in the rolling plane during flight in the desert locust, Schistocerca gregaria. J Exp Biol 43:385-407

Hardie J (1989) Spectral specificity for targeted flight in the black bean aphid, Aphis fabae. J Insect Physiol 35:619-626

Hirama J, Seki K, Hosodani N, Matsui Y (2007) Development of a physical control device for insect pests using a yellow LED light source: results of behavioral observations of the Noctuidae family. J SHITA 19:34-40 (in Japanese)

Hironaka M, Hariyama T (2009) Insect orientation to natural and artificial light. Jpn J Appl Entomol Zool 53:135-145 (in Japanese with English summary)

Honda K (2011) Reactions to light in insects and practical applications. J Soc Biomech 35:233-236 (in Japanese)

Ishikura S (1950) Subsequent fluorescent light trap. J Agric Sci 5:15-19 (in Japanese)

Jander R (1963) Insect orientation. Annu Rev Entomol 8:95-114

Johansen NS, Vänninen I, Pinto DM, Nissinen AI, Shipp L (2011) In the light of new greenhouse technologies: 2. Direct effects of 
artificial lighting on arthropods and integrated pest management in greenhouse crops. Ann Appl Biol 159:1-27

Katayama E, Fukuda T, Nozawa H (1993) Light trap monitoring of the stink bugs attacking fruit trees and their ovarian development. Bull Tochigi Agr Exp Stn 40:59-74 (in Japanese)

Kim MG, Yang JY, Lee HS (2013) Phototactic behavior: repellent effects of cigarette beetle, Lasioderma serricorne (Coleoptera: Anobiidae), to light-emitting diodes. Appl Biol Chem 56: 331-333

Kimura Y (1982) Control of aphid infestation by mulching with silver-colored polyethylene films. Plant Prot 36:469-473 (in Japanese)

Kinoshita M, Arikawa K (2000) Colour constancy in the swallowtail butterfly Papilio xuthus. J Exp Biol 203:3521-3530

Kono S, Yase J (1996) Characteristic of physical control and using technology. Utilization of color sense of insects. Prant Prot 50:30-33 (in Japanese)

Koshitaka H, Kinoshita M, Vorobyev M, Arikawa K (2008) Tetrachromacy in a butterfly that has eight varieties of spectral receptors. Proc R Soc Lond B 275:947-954

Land MF, Nilsson D-E (2002) Animal eyes. Oxford University Press, Oxford, p 271

Legarrea S, Karnieli A, Fereres A, Weintraub PG (2010) Comparison of UV-absorbing nets in pepper crops: spectral properties, effects on plants and pest control. Photochem Photobiol 86:324-330

Mainali BP, Lim UT (2010) Circular yellow sticky trap with black background enhances attraction of Frankliniella occidentalis (Pergande) (Thysanoptera: Thripidae). Appl Entomol Zool 45:207-213

Masaki S (1984) Unity and diversity in insect photoperiodism. In: Photoperiodic regulation of insect and molluscan hormones. CIBA foundation symposium, pp 9-25

Matsumoto Y (1998) Ultraviolet radiation and insect life. Plant Prot 52:77-82 (in Japanese)

Matsumura M (2001) The current status of occurrence and forecasting system of rice planthoppers in Japan. J Asia-Pacific Entomol 4:195-199

Matteson N, Terry I, Ascolichristensen A, Gilbert C (1992) Spectral efficiency of the western flower thrips, Frankliniella occidentalis. J Insect Physiol 38:453-459

Menzel R, Blakers M (1976) Colour receptors in the bee eyemorphology and spectral sensitivity. J Comp Physiol A 108: 11-33

Menzel R, Greggers U (1985) Natural phototaxis and its relationship to colour vision in honeybees. J Comp Physiol A 157:311-321

Meyer-Rochow VB (1974) Fine structural changes in dark-light adaptation in relation to unit studies of an insect compound eye with a crustacean-like rhabdom. J Insect Physiol 20:573-589

Meyer-Rochow VB, Kashiwagi T, Eguchi E (2002) Selective photoreceptor damage in four species of insects induced by experimental exposures to UV-irradiation. Micron 33:23-31

Nagatuka H (2000) Effects of reflective sheet for whiteflies and thrips. Plant Prot 54:359-362 (in Japanese)

Nakagaki S, Sekiguchi K, Onuma K (1982) The growth of vegetable crops and establishment of insect and mite pests in a plastic greenhouse treated to exclude near UV radiation. (2) Establishment of insect and mite pests. Bull Ibaraki Hortic Exp Sta 10:39-47 (in Japanese)

Nakagaki S, Amagai H, Onuma K (1984) The growth of vegetable crops and establishment of insect and mite pests in a plastic greenhouse treated to exclude near UV radiation. (4) Establishment of insect pest on tomatoes. Bull Ibaraki Hortic Exp Sta 12:89-94 (in Japanese)

Neville AC (1960) Aspects of flight mechanics in anisopterous dragonflies. J Exp Biol 37:631-656
Nguyen THN, Borgemeister C, Max J, Poehling HM (2009) Manipulation of ultraviolet light affects immigration behavior of Ceratothripoides claratris (Thysanoptera: Thripidae). J Econ Entomol 102:1559-1566

Nissinen A, Kristoffersen L, Anderbrant O (2008) Physiological state of female and light intensity affect the host-plant selection of carrot psyllid, Trioza apicalis (Hemiptera: Triozidae). Eur J Entomol 105:227-232

Nomura K (1967) Studies on orchard illumination against fruitpiercing moths. III. Inhibition of moths' flying to orchard by illumination. Jpn J Appl Entomol Zool 11:21-28 (in Japanese with English summary)

Nomura K, Oya S, Watanabe I, Kawamura H (1965) Studies on orchard illumination against fruit-piercing moths. I. Analysis of illumination effects, and influence of light elements on moths' activities. Jpn J Appl Entomol Zool 9:179-186 (in Japanese with English summary)

Nonaka K, Nagai K (1985) Pest management using ultravioletabsorbing films. Agric Hortic 60:323-326 (in Japanese)

Ohta I, Kitamura T (2006) Insect pest control by ultraviolet-absorbing plastic films for greenhouse crops. Crop Prod Plast Film 232:3-8 (in Japanese)

Okada Y, Tomioka K, Chiba Y (1991) Circadian phase-response curves for light in nymphal and adult crickets, Gryllus bimaculatus. J Insect Physiol 37(8):583-590

Peitsch D, Fietz A, Hertel H, Souza J, Ventura DF, Menzel R (1992) The spectral input systems of hymenopteran insects and their receptor-based colour vision. J Comp Physiol A 170:23-40

Pittendrigh CS (1993) Temporal organization: reflections of a Darwinian clock-watcher. Annu Rev Physiol 55:17-54

Post CT, Goldsmith TH (1965) Pigment migration and lightadaptation in the eye of the moth, Galleria mellonella. Biol Bull 128:473-487

Prokopy RJ, Owens ED (1983) Visual detection of plants by herbivorous insects. Annu Rev Entomol 28:337-364

Raviv M, Antignus Y (2004) UV radiation effects on pathogens and insect pests of greenhouse-grown crops. Photochem Photobiol 79:219-226

Reisenman CE, Lazzari CR, Giurfa M (1998) Circadian control of photonegative sensitivity in the haematophagous bug Triatoma infestans. J Com Physiol A 183:533-541

Saunders D (2012) Insect photoperiodism: seeing the light. Physiol Entomol 37:207-218

Shimoda M, Kiguchi K (1995) The sweet potato hornworm, Agrius convolvuli, as a new experimental insect: behavior of adult moths in a rearing cage. Jpn J Appl Entomol Zool 39:321-328 (in Japanese with English abstract)

Siderhurst MS, James DM, Bjostad LB (2006) Ultraviolet light induced autophototoxicity and negative phototaxis in Reticulitermes termites (Isoptera: Rhinotermitidae). Sociobiol 48:27-49

Simmons AM, Kousik CS, Levi A (2010) Combining reflective mulch and host plant resistance for sweet potato whitefly (Hemiptera: Aleyrodidae) management in watermelon. Crop Prot 29:898-902

Smith JG (1976) Influence of crop background on aphids and other phytophagous insects on Brussels sprouts. Ann Appl Biol 83:1-13

Stark WS, Walker KD, Eidel JM (1985) Ultraviolet and blue light induced damage to the Drosophila retina: microspectrophotometry and electrophysiology. Curr Eye Res 4:1059-1075

Tazawa S (2009) Artificial lighting for agricultural applications. J Jpn Soc Agric Machin 71:19-25 (in Japanese)

Tokumaru S, Higuchi T, Taguchi Y (2009) Control of the whiteflies, Trialeurodes vaporariorum and Bemisia tabaci, in tomato greenhouse by yellow sticky long film. Ann Rept Kansai Plant Prot 51:87-88 (in Japanese) 
Truman JW (1976) Extraretinal photoreception in insects. Photochem Photobiol 23:215-225

Tsuchiya M, Masui S, Kuboyama N (1995) Reduction of populationdensity of yellow tea thrips (Scirtothrips dorsalis Hood) on mandarin orange (Citrus unshiu Marc.) trees by application of white solution with or without reflective sheet mulching. Jpn J Appl Entomol Zool 39:305-312 (in Japanese with English abstract)

Vaishampayan SM, Kogan M, Waldbauer GP, Wooley JT (1975) Spectral specific responses in the visual beaviour of the greenhouse whitefly, Trialeurodes vaporariorum (Homoptera: Aleurodidae). Entomol Exp Appl 18:344-356

von Helversen O (1972) Zur spektralen Unterschiedsempfindlichkeit der Honigbiene. J Comp Physiol A 80:439-472

Walcott B (1969) Movement of retinula cells in insect eyes on light adaptation. Nature 223:971-972

Yabu T (1999) Control of insect pests by using illuminator of ultra high luminance light emitting diode (LED). Effect of the illumination on the flight and mating behavior of Helicoverpa armigera. Plant Prot 53:209-211 (in Japanese)

Yamada M, Uchida T, KUramitsu O, Kosaka S, Nishimura T, Arikawa $\mathrm{K}$ (2006) Insect control lighting for reduced and insecticide-free agriculture. Matsushita-Denko-Giho 54(1):30-35 (in Japanese with English summary)
Yang EC, Lee DW, Wu WY (2003) Action spectra of phototactic responses of the flea beetle, Phyllotreta striolata. Physiol Entomol 28:362-368

Yase J, Yamanaka M, Fujii H, Kosaka S (1997) Control of tobacco budworm, Helicoverpa armigera (Hubner), beet armyworm, Spodoptera exigua (Hubner), common cutworm, Spodoptera litura (Fabricius), feeding on carnation, roses and chrysanthemum by overnight illumination with yellow fluoresent lamps. Bull Natl Agric Res Cent West Reg 93:10-14 (in Japanese)

Yase J, Nagaoka O, Futai K, Izumida T, Kosaka S (2004) Control of cabbage webworm, Hellula undalis Fabricius (Lepidoptera: Pyralidae) using yellow fluorescent lamps. Jpn J Appl Entomol Zool Chugoku Bra 46:29-37 (in Japanese with English abstract)

Yoon JB, Nomura M, Ishikura S (2012) Analysis of the flight activity of the cotton bollworm Helicoverpa armigera (Hubner)(Lepidoptera: Noctuidae) under yellow LED lighting. Jpn J Appl Entomol Zool 56:103-110 (in Japanese with English summary)

Zhang CY, Meng JY, Wang XP, Zhu F, Lei CL (2011) Effects of UVA exposures on longevity and reproduction in Helicoverpa armigera, and on the development of its F1 generation. Insect Sci 18:697-702 